\title{
A New Faraday Rotation Measurement Method for the Study on Magneto Optical Property of $\mathrm{PbO}-\mathrm{Bi}_{2} \mathrm{O}_{3}-\mathrm{B}_{2} \mathrm{O}_{3}$ Glasses for Current Sensor Applications
}

\author{
Qiuling Chen, Qiuping Chen, Shuangbao Wang \\ Department of Materials Science and Chemical Engineering, Politecnico di Torino, Torino, Italy \\ E-mail: Qiuling.chen@polito.it \\ Received August 17, 2011; revised September 19, 2011; accepted September 28, 2011
}

\begin{abstract}
MAGNETO-OPTICAL current transformers (MOCT) based on the Faraday Effect provide numerous advantages over the conventional transformers. However the commonly used materials in MOCT are crystals that are very expensive and temperature dependence thus will cause many problems for the output signal. Cost efficient diamagnetic $\mathrm{PbO}-\mathrm{Bi}_{2} \mathrm{O}_{3}-\mathrm{B}_{2} \mathrm{O}_{3}$ (PBB) glass system is fabricated in this study, for the aim of obtaining a good candidate glass with high Verdet constant and good temperature resistance to replace crystals. A home-made optical bench was setup, calibrated and used for measuring the Verdet constant of the fabricated glasses. Glass with composition of $50 \% \mathrm{PbO}-40 \% \mathrm{Bi}_{2} \mathrm{O}_{3}-10 \% \mathrm{~B}_{2} \mathrm{O}_{3}$ in mol showed high Verdet constant $\left(0.1533 \mathrm{~min} \cdot \mathrm{G}^{-1} \cdot \mathrm{cm}^{-1}\right)$ and good value of the figure of merit $\left(0.02635 \mathrm{~min} \cdot \mathrm{G}^{-1}\right)$, which can be considered as the ideal candidate for MOCT applications.
\end{abstract}

Keywords: MOCT, Magnetic Optical Glass, Verdet Constant

\section{Introduction}

MAGNETO-OPTICAL current transformers (MOCT's) based on the Faraday Effect provide numerous advantages over the conventional transformers. The measurements are contactless, small volume and cost efficient. It is hopeful for MOCT can find much wider applications especially in automobile industry [1,2]. However commonly used materials for MOCT are crystals which are very expensive and temperature dependence [3,4]. On the other hand, low cost glass with good optical-magnetic properties (e.g. high Verdet constant and figure of merit etc.) is required greatly [5-7].

Literatures on glasses based on heavy metal oxides for the above application have been reported [1,2]. Especially the oxide glasses with lead and bismuth oxides, due to the big mass and polarizability of ions $\mathrm{Pb}^{2+}$ and $\mathrm{Bi}^{3+}$ belong to diamagnetism glass and has good temperature resistance, smaller phonon energy and larger refraction indices $[2,4]$ comparing to borosilicate, phosphate and silicate glasses. Based on previous study carried out by the authors [1,5], a $\mathrm{PbO}-\mathrm{Bi}_{2} \mathrm{O}_{3}-\mathrm{B}_{2} \mathrm{O}_{3}$ (PBB) based glass system was chosen for this study with the aim of obtaining a good candidate for MOCT design.
Concerning the measurement of Faraday rotation, the conventional double light way method is complex due to the use of lock-in amplifier and computer assisted detector system and so on $[8,9]$. In this study, a home-made single light way method was setup, calibrated and used to measure the Verdet constant of the glass, the advantage of this optical bench is single and low cost: no needs the lock-in amplifier, the detector is a power meter. The magnetic field is induced by solenoids on which the current will be applied by a DC supplier. Through the optical bench, the magneto optical properties of the glasses were studied.

\section{Experiments}

\subsection{Glass Fabrication and Characterization}

The compositions of the prepared glass are listed in Table 1. Synthesis was carried out in ceramic crucibles in an electric oven at the temperature at around $900^{\circ} \mathrm{C}$ followed with stirring during melting. The melted mass was poured into a cast brass form and then relief annealed. Samples used for studies were cut into $\phi 10 \mathrm{~mm}$ $\times 2 \mathrm{~mm}$ slides and polished using Logitech PM5. From 
many samples of different percantage of oxides, the one with optimum composition assuring the best optical and magnetic properties was chosen.

The refractive indexes of samples were measured using a prism coupling method (Metricon Model 2010 M). The absorption spectra in ultraviolet-visible region $(200-2000 \mathrm{~nm})$ were recorded for each sample using a UV-Visible-IR spectrophotometer (Varian Cary 500). Optical energy gap for the studied glasses were evaluated from relation $(\alpha \mathrm{h} v)^{1 / 2}=\mathrm{B}^{1 / 2}\left(h v-\mathrm{E}_{\mathrm{g}}\right)$, where $\mathrm{B}^{1 / 2}$ is the slope of the absorption edge reflecting the sample disorder $[10,11]$ and hu is the photon energy. On the absorption edge the slope line was extended and cross onto horizontal axis (wavelength), the crossing-point means the absorption threshold wavelength.

Raman spectra were measured using a MKI Renishaw Raman spectroscopy equipped with a BH2-UMA Olympus microscope between $200 \mathrm{~cm}^{-1}$ to $2000 \mathrm{~cm}^{-1}$.

\subsection{Faraday Effect Measurements on Glasses}

\subsubsection{Optical Bench Setup}

Figure 1 schematically shows the setup for the Verdet constant measurement. In order to investigate the Faraday Effect of the fabricated PBB glasses, a home-made Faraday Effect test apparatus is built up: a He-Ne laser with $15 \mathrm{Mw}$ power at $632.8 \mathrm{~nm}$ wavelength was used as the light source, a $100 \%$ refection mirror was used to change the light way to a polarizer which polarized the incident light beam to pass the glass which was placed in a 320 turns solenoid. The polarizers, solenoids and powermeter detector are integrated in a dark box (dotted line) to avoid the background light and reduce the noise (two polarizers were set in $90^{\circ}$ to each other in orientation).

\subsubsection{Measurement and Calculation}

Due to the Faraday rotation, an angle will happened under the magnetic field $\mathrm{B}$, the output intensity of the current is different from that of without $\mathrm{B}$. The difference between

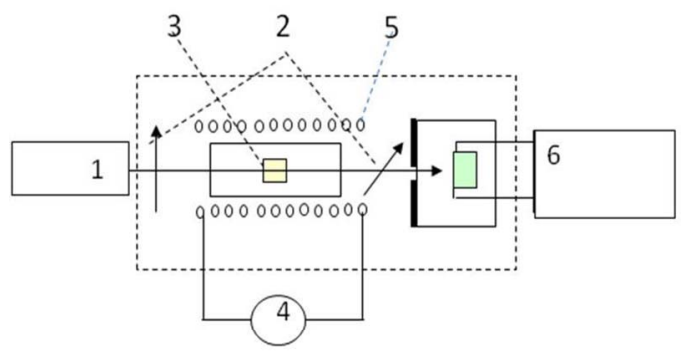

Figure 1. Schematic diagram of optical bench set-up for Faraday rotation measurement, 1. He-Ne Laser; 2. Polarizers; 3. Bulk glass; 4. DC supplier; 5. Solenoide; 6. Power meter. the two values is named $\Delta \mathrm{I}$. The $\mathrm{I}, \mathrm{I}_{0}$, the rotated angle $\theta$, and the Verdet constant of glass $\mathrm{V}$, meet the following relationship:

$$
\begin{gathered}
\mathrm{I}=\mathrm{I}_{0} \cos ^{2}(\mathrm{a}+\theta) \\
\Delta \mathrm{I}=\mathrm{I}_{0} \sin ^{2}(\theta) \propto \mathrm{I}_{0} \theta^{2}\left(\text { while } \mathrm{a}=90^{\circ}\right) \\
\mathrm{q}=\mathrm{VBL} \\
\mathrm{B}=\mu_{0} \mathrm{NI} / \mathrm{L}_{\mathrm{s}}
\end{gathered}
$$

where I is the detected transmission light intensity without magnetic field, $\mathrm{I}_{0}$ is the original incident light intensity with the magnetic field applied, a is the angle between two polarizes without magnetic field, $\mathrm{L}$ is the sample length, $\mu_{0}$ is the constant $\left(1.26 \times 10^{-6} \mathrm{~B} \cdot \mathrm{m}^{-1}\right), \mathrm{N}$ is the turns of solenoids, I is the applied current, Ls is the length of solenoids. Through the detected output light intensity ( $\mathrm{I}$ and $\mathrm{I}_{0}$ ), the rotated angle $\theta$ could be obtained according to Equations (1) and (2). B could be obtained through the Equation (4). And according to Equation (3), the V can be calculated.

\subsubsection{Uniformity Test of Magnetic Field}

The magnetic field $\mathrm{B}$ was induced by the DC supplier. The current was set as $1 \mathrm{~A} \mathrm{DC}$, and the light intensity I and $\mathrm{I}_{0}$, represented the output voltage values from detector before and after the switch on of the DC circuit, respectively; through the switch on and off the current, a magnetic field will be induced or disappeared in the solenoid.

The uniformity and homogenous of B inside the solenoids was tested using the magnetometer. The length of solenoid is around $0.2 \mathrm{~m}$. The B in every one centimeter from the middle of the solenoid to two ends was measured using magnetometer. Figure 2 shows the distribution profile of the $\mathrm{B}$ in different position of the solenoids. It can be seen that the inner magnetic field of solenoid is uniform.

The relationship between applied current I and the change of B also was measured for the aim of verify the uniformity of $B$ inside the solenoids. Changing the applied current, different B in the middle of solenoid was obtained from magnetometer. Figure 3 shows the changes of $\mathrm{B}$ under different current I. The relationship between them is a linear which proved again the B inside the solenoids is homogenous and uniform.

\subsubsection{Calibration of Optical Bench}

Calibration of the set up was performed using a standard pure silica sample (its Verdet Constant $=0.01352$ $\min \cdot G^{-1} \cdot \mathrm{cm}^{-1}$ from literatures [9]). Every time before measuring the glasses, under the same condition the pure silica was put inside the solenoids, with and without $\mathrm{B}$, the output of intensity of current was recorded and calcula- 


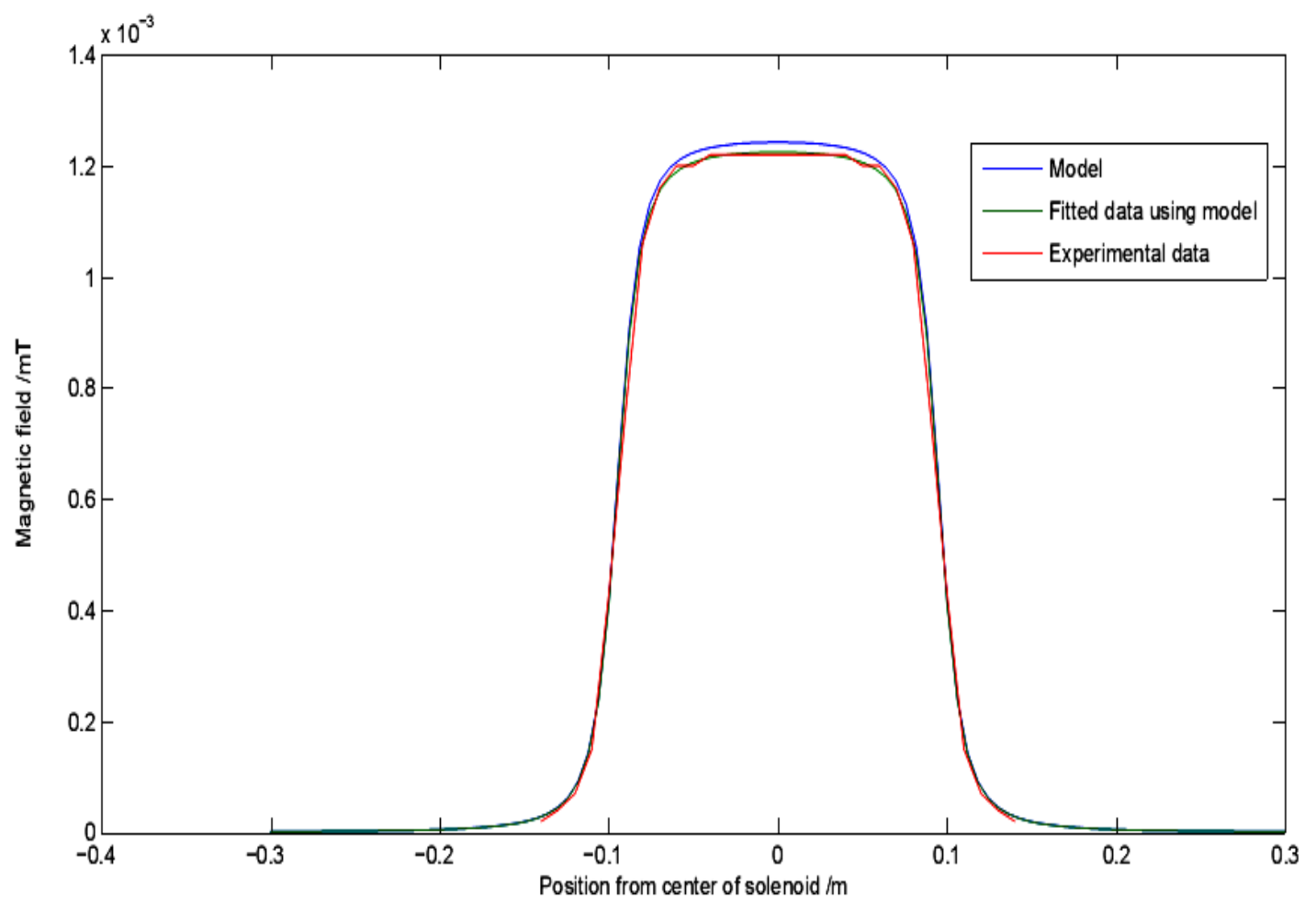

Figure 2. Distribution profile of the $B$ in different position of the solenoids.

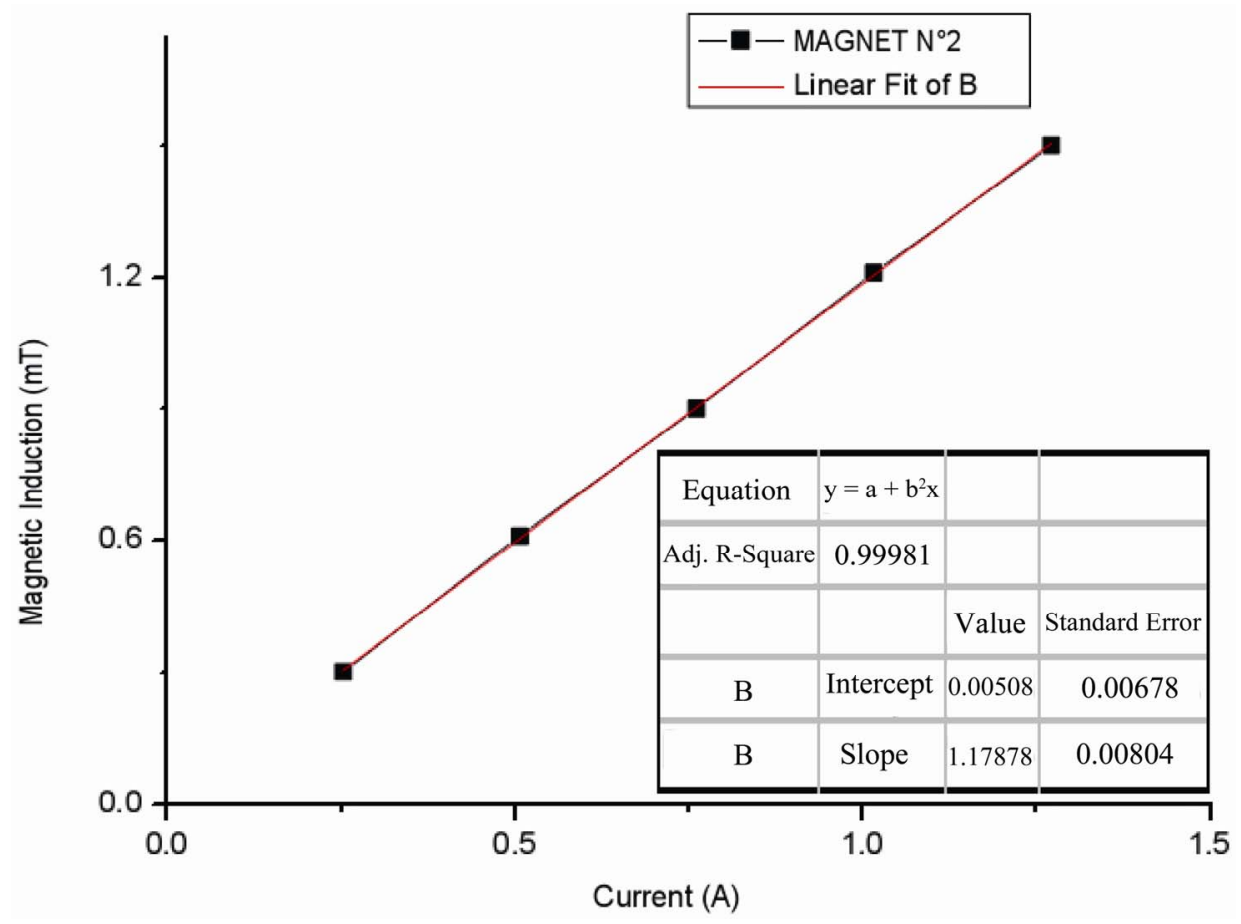

Figure 3. Magnetic field B vs current I.

ted. Compare to its value of $0.01352 \mathrm{~min} \cdot \mathrm{G}^{-1} \cdot \mathrm{cm}^{-1}$, if the measured value is not exceed 0.001 error rate, this proved that the optical bench is ok for use.

\section{Results}

Table 1 reports the composition of prepared glasses and 
Table 1. Magnetic-optical properties of the PBB glass samples.

\begin{tabular}{ccccccc}
\hline Glass & PBB01 & PBB2 & PBB03 & PBB4 & PBB5 & PBB06 \\
\hline Composition* & $50-40-1040-50-1020-70-1035-45-20$ & $15-65-2025-35-40$ \\
\hline $\mathrm{V}\left(\mathrm{min} \cdot \mathrm{G}^{-1} \cdot \mathrm{cm}^{-1}\right)$ & 0.1533 & 0.1153 & 0.1105 & 0.083 & 0.083 & 0.0505 \\
Cutoff $(\mathrm{nm})$ & 474.85 & 471.27 & 469.84 & 448.38 & 458.39 & 406.16 \\
$\mathrm{Q}\left(\mathrm{min} \cdot \mathrm{G}^{-1}\right)$ & 0.026 & 0.016 & 0.015 & 0.014 & 0.014 & 0.012 \\
$\mathrm{~T}_{\mathrm{g}}\left({ }^{\circ} \mathrm{C}\right)$ & 289 & 293 & 292 & 307 & 315 & 327 \\
$\mathrm{~T}_{\mathrm{x}}-\mathrm{T}_{\mathrm{g}}\left({ }^{\circ} \mathrm{C}\right)$ & 81 & 63 & 61 & 100 & 58 & 101 \\
$\mathrm{n} @ 633 \mathrm{~nm}$ & 2.374 & 2.357 & 2.139 & 2.215 & 2.059 & 2.002 \\
$\rho\left(\mathrm{g} / \mathrm{cm}^{-3}\right)$ & 8.33 & 8.33 & 8.31 & 7.85 & 8.03 & 6.57 \\
\hline
\end{tabular}

*Composition of $\mathrm{PBB}$ is in mol: $\mathrm{PbO}-\mathrm{Bi}_{2} \mathrm{O}_{3}-\mathrm{B}_{2} \mathrm{O}_{3}$.

their thermal and magneto optical properties, including the $T_{g}$, refractive index, Verdet constant, cutoff, the figure of merit and so on. The difference of $T_{x}$ and $T_{g}$ is usually used to evaluate the thermal stability of the glasses, generally speaking, the bigger the difference, the more stable of the glass.

\subsection{UV-Vis and FT-IR Spectra Analysis}

Figure 4 shows the absorption spectra in the UV-visible region of all glasses. The absorption coefficient, cutoff changed strongly with the glass composition. The cutoff shifted to longer wavelength with the increasing of total amount of $\mathrm{PbO}+\mathrm{Bi}_{2} \mathrm{O}_{3}$. Glass $\mathrm{PBB} 01$ showed the biggest cutoff and lower absorption compared with other samples. Figure 5 shows the FT-IR spectra analysis on the prepared glasses. PBB01 showed more than $70 \%$ of transmittance during $2000 \mathrm{~nm}$ to $4000 \mathrm{~nm}$. The peak around $3300 \mathrm{~nm}$ is due to the $\mathrm{OH}$ absorption. With the increase of $\mathrm{PbO}$ and $\mathrm{Bi}_{2} \mathrm{O}_{3}$ content, the spectrum exhibits a shift to longer wavelength.

\subsection{Verdet Constants and the Figure of Merit}

The magnetic optical property of fabricated glasses is

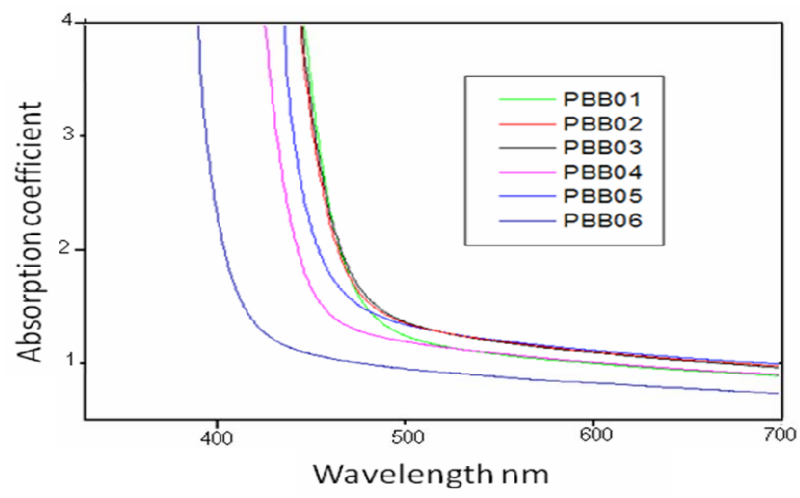

Figure 4. UV-visible absorption spectra of the PBB glasses.

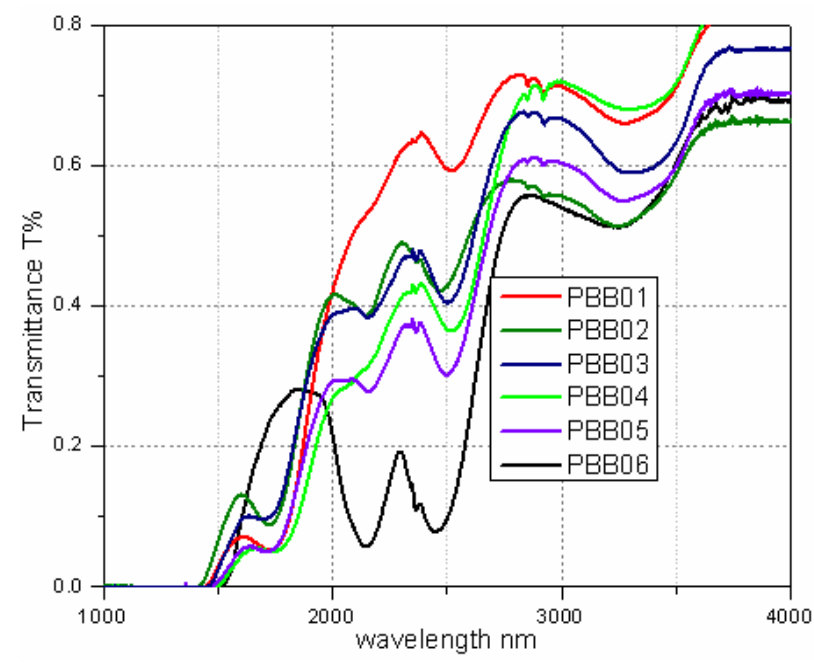

Figure 5. FT-IR transmittance spectra of the PBB glasses.

evaluated in term of Verdet constant $\mathrm{V}$ and the figure of merit $\mathrm{Q}$. The relationship between $\mathrm{V}$ and $\mathrm{Q}$ is: $\mathrm{Q}=\mathrm{V} / \alpha$, where $\alpha$ is the absorption coefficient which was obtained from Figure 4. Table 1 reports the Verdet constant for all the glass samples, along with their cutoff and figure of merit. Figure 4 shows the relationship between Verdet constant and the cutoff. The PBB01 showed the highest value of Verdet constant e.g. $0.1533 \mathrm{~min} \cdot \mathrm{G}^{-1} \cdot \mathrm{cm}^{-1}$, the largest cutoff wavelength of $474.85 \mathrm{~nm}$ and the best $\mathrm{Q}$ of $0.02635 \mathrm{~min} \cdot \mathrm{G}^{-1}$.

\subsection{Raman Spectra}

The change of glass properties is due to the change of glass structures. Figure 7 reports the change of structures for all samples. There are mainly five peaks named as, A $\left(400 \mathrm{~cm}^{-1}\right), \mathrm{B}\left(550 \mathrm{~cm}^{-1}\right), \mathrm{C}\left(710 \mathrm{~cm}^{-1}\right), \mathrm{D}\left(920 \mathrm{~cm}^{-1}\right)$ and a broad band (E) around $1220 \mathrm{~cm}^{-1}$. A significant change in spectrum both for the shape and intensity was observed. PBB01 showed the highest intensity of peaks for A $\left(400 \mathrm{~cm}^{-1}\right)$ and B $\left(550 \mathrm{~cm}^{-1}\right)$, and PBB06 showed the lowest intensity of the same peaks.

The presences of different peaks for heavy metal oxides glasses at different wavelength, for example, 300 $600 \mathrm{~cm}^{-1}$, especially vibrations between $380-580 \mathrm{~cm}^{-1}$ due to the bridging anion modes, and $650-950 \mathrm{~cm}^{-1}$ due to the non-bridging anion modes [12]. Bismuth and lead cations have similar atomic weight, they have similar polarization behaviors. The peak A and B in Figure 7 correspond to the "bridge-anion" motion due to symmetric stretch motion of $\mathrm{Bi}-\mathrm{O}-\mathrm{Bi}$ and $\mathrm{Pb}-\mathrm{O}-\mathrm{Pb}$ bridges combined with some $\mathrm{Bi}-\mathrm{O}-\mathrm{Pb}$.

A broadening at around $1250 \mathrm{~cm}^{-1}$ which is named as E peak is attributed mainly to trigonal boron $\left[\mathrm{BO}_{3}\right][13$, 14]. With the change of content of $\mathrm{B}_{2} \mathrm{O}_{3}$ in the glass, a 
slight change for the peak E was also observed.

\section{Discussion}

Samples with different compositions presented different thermal and magneto optical properties as showed previously. The Verdet constant of the glasses, which was measured using the home-made optical bench, has relation with the composition, energy gap and cutoff of the glasses.

\subsection{Relationship between Verdet Constant and Composition}

It is know that the Verdet constant of a magnetic-optical material is related to the electron shell structure of the atoms in the transparent medium. If the ions have the electron structure same with inert gas, the applied field can induce the Zeeman splitting on the ion energy levels. The resulting rotation of the polarized plane is diamagnetism, and the rotating angle $\theta$ is positive; the applied field can induce the moment of force of electrons change in the ions which have unpaired electrons. Basing on the classical electromagnetism theory $[15,16]$, Bacquerel has proposed the relationship between the Verdet constant of a diamagnetic material and the properties of the materials as shown in the following equation:

$$
\mathrm{V}=(\mathrm{e} / 2 \mathrm{mc}) \lambda \frac{\mathrm{d} n}{\mathrm{~d} \lambda}
$$

Here, $\mathrm{V}$ is the Verdet constant, $n$ is the refraction index of the material; $\mathrm{d} n / \mathrm{d} \lambda$ is the dispersion of the material; e is electron's electrical quant, $\mathrm{m}$ is the electron mass, $\mathrm{c}$ is light speed and $\lambda$ is the corresponding light wavelength. From this Equation (5), it can be seen that Verdet constant of the diamagnetic material becomes higher when the dispersion of the material increases. In fact, the presence of heavy metal ions such as $\mathrm{Pb}^{2+}, \mathrm{Bi}^{3+}$ in the glasses could contribute greatly to the color dispersion of the glasses. Therefore, the increase of the total amount of these ions in the glasses will not only lead to the shift of their cutoff, but also the increase of Verdet constant.

Basing on the quantum theory $[7,15]$ the Verdet constant of the diamagnetic material is also related to the ion carriers with energy level splitting possibility as demonstrated in the following formulary (6):

$$
\mathrm{V}=\left(4 \pi N \mathrm{v}^{2}\right) \sum_{\mathrm{n}}\left[\mathrm{A}_{\mathrm{n}} /\left(\mathrm{v}^{2}-\mathrm{v}_{\mathrm{n}}^{2}\right)^{2}\right]
$$

Here $N$ is the carriers in per unit volume; $v$ : frequency of the incident wave; $v_{n}$ is the frequency of electrons migration; $A_{n}$ is parameters correlative with migration intensity.
The formulary (6) shows that the Verdet constant of a diamagnetic material is related to the carriers' concentration $N$, in the case of this study, the $\mathrm{Pb}^{2+}$ and $\mathrm{Bi}^{3+}$ ions are the carriers. Therefore glasses containing higher density of $\mathrm{Pb}^{2+}$ and $\mathrm{Bi}^{3+}$ ions such as PBB01 will show higher Verdet constant.

From the formulary (6), it is also noted that the Verdet constant of a diamagnetic material has no relationship with the working temperature. This is ideal for MOCT, which makes this PBB glass have great advantages over the currently used crystal for MOCT.

\subsection{Relationship between Verdet Constant and Energy Gap}

From Figure 6 and Table 1, it can be seen that the Verdet constant also has relationship with cutoff, and the cutoff of glass is related to the energy required for the electron transition of glass network former from unexcited states to excited states. Therefore the shift of cutoff for PBB glasses depended strongly on the change of the total amount of $\mathrm{PbO}+\mathrm{Bi}_{2} \mathrm{O}_{3}$ in the glass, which in fact act as both glass network former and modifiers [1,5]. On the other hand, with the decrease of $\mathrm{B}_{2} \mathrm{O}_{3}$ content which acts as glass network former, the glass network structure will be significantly modified, as it can be seen also from the Raman Spectra in Figure 7. In fact, heavy metal ions such like $\mathrm{Pb}^{2+}$, and $\mathrm{Bi}^{3+}$ play important roles in the glass as network modifiers that weaken the bridged $\mathrm{O}-\mathrm{B}$ bonds. With increasing of $\mathrm{PbO}+\mathrm{Bi}_{2} \mathrm{O}_{3}$ content, an increase of structural disorder occurred (the $\mathrm{PbO}$ could also behavior as network formers, considering the difference between $\mathrm{PbO}$ and $\mathrm{Bi}_{2} \mathrm{O}_{3}$ ), and various non-bridged centers inside the network will be produced. As a consequence the energy required for breaking down the glass network of $\mathrm{OB}$ bond will be decreased which leads to the shift of the cu-

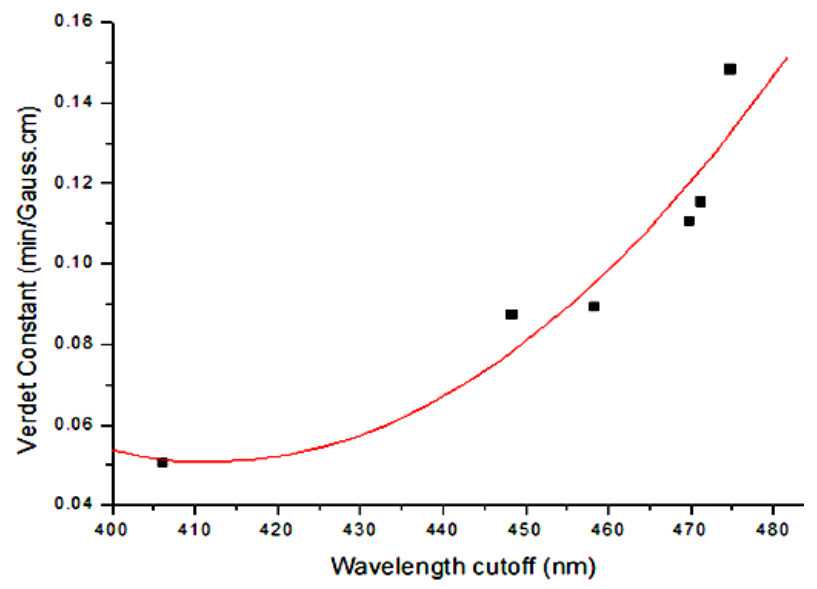

Figure 6. The relationship between the Verdet constant and cutoff. 


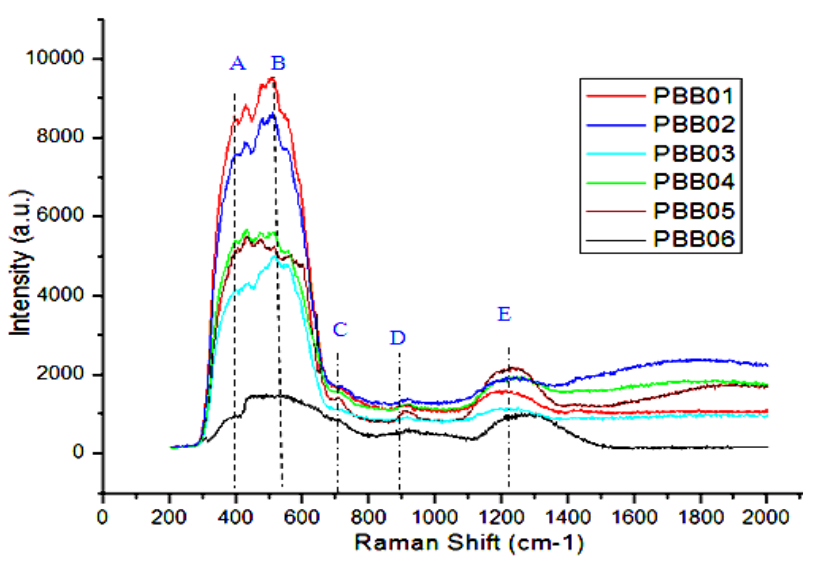

Figure 7. The Raman spectra of PPB MO glasses.

toff towards longer wavelength. Such a shift in cutoff could also be explained by the change of band gap for different constituents in glass systems: it is found that the band gap for $\mathrm{B}_{2} \mathrm{O}_{3}$ is. $\mathrm{E}_{\mathrm{g}}\left(\mathrm{B}_{2} \mathrm{O}_{3}\right) \approx 8 \mathrm{eV}$ [17], for $\mathrm{PbO}$ is $\mathrm{E}_{\mathrm{g}}(\mathrm{PbO}) \approx 2.73 \mathrm{eV}$ [17] and for $\mathrm{Bi}_{2} \mathrm{O}_{3}$ is $\mathrm{E}_{\mathrm{g}} \mathrm{E}_{\mathrm{g}}\left(\mathrm{Bi}_{2} \mathrm{O}_{3}\right) \approx$ 2.76eV [18]. The increase of $\mathrm{PbO}+\mathrm{Bi}_{2} \mathrm{O}_{3}$ and decrease of $\mathrm{B}_{2} \mathrm{O}_{3}$ in the glass will therefore decrease the band gap of glasses, which means the decrease of energy gap caused the increase of Verdet constant. A similar phenomenon was reported by Y. L. Ruan et al [15] for the relationship between Verdet constant and band gap for chalcogenide system glass.

\section{Conclusions}

A new way for Faraday rotation measurement was used for the study on magneto optical property of PBB glass for MOCT application was carried out. A relationship between Verdet constant and the glass composition has been identified and it is found that with the shift of cutoff of UV absorption to longer wavelength, the Verdet con- stant of the glasses increased. The optimized glass PBB01 with the composition of $\left(50 \% \mathrm{PbO}-40 \% \mathrm{Bi}_{2} \mathrm{O}_{3}-10 \% \mathrm{~B}_{2} \mathrm{O}_{3}\right)$ shown the largest value of Verdet constant $\left(0.1533 \mathrm{~min} \cdot \mathrm{G}^{-1} \cdot \mathrm{cm}^{-1}\right)$, and good value of the figure of merit $\left(0.02635 \mathrm{~min} \cdot \mathrm{G}^{-1}\right)$, which can be considered as the candidate as magneto optical devices application.

\section{References}

[1] Q. Chen, M. Ferraris, D. Milanese, et al., "Novel Er-Doped $\mathrm{PbO}$ and $\mathrm{B}_{2} \mathrm{O}_{3}$ Based Glasses: Investigation of Quantum Efficiency and Non-Radiative Transition Probability for 1.5 Mm Broadband Emission Fluorescence," Journal of Non-Crystalline Solids, Vol. 324, No. 1-2, 2003, pp. 12-20. doi:10.1016/S0022-3093(03)00223-0

[2] P. Ripka, "Current Sensors Using Magnetic Materials," Journal of Optoelectronics and Advanced Materials, Vol.
6, No. 2, 2004, pp. 587-592.

[3] Y. S. Didosyan and H. Hauser, "Magneto-Optical Current Sensor by Domain Wall Motion in Orthoferrites," Ieee Transactions on Instrument and Measurement, Vol. 49, No. 1, 2000, pp.14-18. doi:10.1109/19.836301

[4] Y. S. Didosyan, H. Hauser and W. Toriser, "Temperature Characteristics of a New Magneto-Optical Current Transformer," International Journal of Applied Electromagnetics and Mechanics, Vol. 13, No. 1-4, 2001-2002, pp. $227-$ 283.

[5] Q. P. Chen, M. Ferraris, et al., "Novel Erbium Doped PbO and $\mathrm{B}_{2} \mathrm{O}_{3}$ Based Glasses with Broad $1.5 \mu \mathrm{m}$ Absorption Line Width and Low Refractive Index," Journal of NonCrystalline Solids, Vol. 324, No. 1-2, 2003, pp. 1-11. doi:10.1016/S0022-3093(03)00222-9

[6] W. N. Li, K. S. Zou, M. Lu, B. Peng, and W. Zhao, "Faraday Glasses with a Large Size and High Performance," International Journal of Applied Ceramic Technology, Vol. 7, No. 3, 2010, pp. 369-374.

doi:10.1111/j.1744-7402.2008.02344.x

[7] C. B. Pedroso, E. Munin, A. B. Villaverde, et al., "Magneto-Optical Rotation of Heavy-Metal Oxide Glasses," Journal of Non-Crystalline Solids, Vol. 231, No. 1-2, 1998, pp. 134-142. doi:10.1016/S0022-3093(98)00408-6

[8] A. A. Kharlamov, R. M. Almeida and H. Jong, "Vibrational Spectra and Structure of Heavy Metal Oxide Glasses," Journal of Non-Crystalline Solids, Vol. 202, No. 3, 1996, pp. 233- 240. doi:10.1016/0022-3093(96)00192-5

[9] C. Z. Tan and J. Arndt, "Faraday Effect in Silica Glasses," Journal of Physics B, Vol. 233, No. 1, 1997, pp. 1-7. doi:10.1016/S0921-4526(97)80001-T

[10] E. A. Davis and N. F. Mott, "Conduction in Non-Brystalline Systems V. Conductivity, Optical Absorption and Photoconductivity in Amorphous Semiconductors," Philosophical Magazine, Vol. 22, No. 179, 1970, pp. 903-922. doi:10.1080/14786437008221061

[11] Y. Cheng, H. Xiao, et al., "Structure and Crystallization Kinetics of $\mathrm{PbO}-\mathrm{B}_{2} \mathrm{O}_{3}$ Glasses," Ceramics International, Vol. 33, No. 7, 2007, pp. 1341-1347. doi:10.1016/j.ceramint.2006.04.025

[12] M. E. Lines, "Oxide Glasses for Fast Photonic Switching: A Comparative Study," Journal of Applied Physics, Vol. 69, No. 10, 1991, pp. 6876-6884. doi:10.1063/1.347677

[13] K. Knoblochova, H. Ticha, J. Schwarz and L. Tichy, "Raman Spectra and Optical Properties of Selected $\mathrm{Bi}_{2} \mathrm{O}_{3}-\mathrm{PbO}-\mathrm{B}_{2} \mathrm{O}_{3}-\mathrm{GeO}_{2}$ Gasses," Optical Materials, Vol. 31, No. 6, 2009, pp. 895-898. doi:10.1016/j.optmat.2008.10.024

[14] K. Kotkova, H. Ticha and L. Tichy, "Raman Studies and Op- tical Properties of Some $(\mathrm{PbO})_{x}\left(\mathrm{Bi}_{2} \mathrm{O}_{3}\right)_{0.2}\left(\mathrm{~B}_{2} \mathrm{O}_{3}\right)_{0.8-x}$ Gla- sses," Journal of Raman Spectroscopy, Vol. 39, No. 9, 2008, pp. 12-19. doi:10.1002/jrs.1969

[15] Y. Ruan, R. A. Jarvis, et al., "Wavelength Dispersion of Verdet Constants in Chalcogenide Glasses for MagnetoOptical Waveguide Devices," Optics Communications, Vol. 252, No. 1-3, 2005, pp. 39-45. 
doi:10.1016/i.optcom.2005.03.037

[16] C. B. Peroso, E. Munin, et al., "Magneto-Optical Rotation of Heavy-Metal Oxide Glasses," Journal of Non-Crystalline Solids, Vol. 231, No. 1-2, 1998, pp. 134-142.

doi:10.1016/S0022-3093(98)00408-6

[17] T. Watadabe, K. Muratsubaki, et al., "Hardness and Elas$\mathrm{p}\left[\right.$ tic Properties of $\mathrm{Bi}_{2} \mathrm{O}_{3}$-based Glasses," Journal of Mate- rials Science, Vol. 36, No. 10, 2001, pp. 2427-2433. doi:10.1023/A:1017973830342

[18] E. Munin, A. B. Villaverde, et al., "Magneto-Optical Rotation of Heavy-Metal Oxide Glasses," Journal of Non-Crystalline Solids, Vol. 231, No. 1-2, 1998, pp. 134-142. doi:10.1016/S0022-3093(98)00408-6 